Article - Food/Feed Science and Technology

\title{
Characterization of Seed Oils of Pterodon emarginatus Vogel (Sucupira) Obtained by Different Extraction Methods
}

Tainara Costa-Singh ${ }^{1}$

https://orcid.org/0000-0002-7718-8094

Neuza Jorge ${ }^{1^{*}}$

https://orcid.org/0000-0001-7166-0880

'São Paulo State University, Department of Food Engineering and Technology, 15054-000, São José do Rio Preto, São Paulo, Brazil..

Received: 2017.11.30; Accepted: 2019.07.13.

*Correspondence: neuza.jorge@unesp.br; Tel.: +55-17-32212257

\section{HIGHLIGHTS}

- The oils of sucupira seeds are good sources of oleic, lauric, and capric fatty acids

- Viable sources of bioactives compounds with high antioxidant activity and oxidative stability.

- The application of raw materials for the food and pharmaceutical industries may be suggested.

\begin{abstract}
The present study aims to evaluate the influence of extraction methods on the quality of bioactive compounds and antioxidant capacity in Pterodon emarginatusVogel (sucupira) oils. The oils were extracted from the sucupira seeds by Soxhlet and by the extraction system of Bligh \& Dyer. The oils were analyzed as to fatty acid profile, tocopherols, phytosterols, carotenoids, total phenolics, and total antioxidant capacity. The extraction by Soxhlet showed better yield of total lipids and was more efficient to extract tocopherols, phytosterols, and carotenoids, besides presenting better antioxidant activity by DPPH. However, this method showed insufficient capacity to extract the polar lipid components of the sample, as evidenced by the low results of total phenolic compounds. On the other hand, the Bligh \& Dyer method preserved the fatty acid profile and was also effective to extract higher phenolic compounds content and presented superior antioxidant activity when assessed by FRAP, ABTS ${ }^{\circ}$, and oxidative stability index.
\end{abstract}


Keywords: Antioxidants; Bioactives; Extraction; Oxidative stability; Chromatography.

\section{INTRODUCTION}

The species Pterodon emarginatus Vogel, popularly known as white sucupira or faveira, is a tree which is native to the Brazilian Cerrado. It can be found in the states of Minas Gerais, São Paulo, Goiás, and Mato Grosso do Sul and is especially notable for being of medicinal and forestry importance. This species produces large quantities of viable seeds, which can eventually be attacked by insects. Flowering occurs during the months of September and October, and fruit ripening happens in June and July, when the plant is almost completely stripped of foliage. The seeds can be harvested directly from the tree or when they begin to fall spontaneously on the ground [1].

The population makes use of the seeds in hydroalcoholic maceration in order to treat laryngological diseases and to use in infant compounds, such as energizing medications or appetite stimulants [2]. Seeds of $P$. emarginatus are also used as raw material to obtain an amber-colored viscous oil that has been considered a rich source of diterpenes from the vouacapane type [3-5]. The seed oil also makes the use in the treatment of sore throats [6] and gynecological infections [7]. Its use has also been reported as having anti-inflammatory and purifying functions [8]. In addition to the anti-inflammatory activity [9], the seed oil also presents protection against oxidative stress [10]. The stems have been used in the treatment of diabetes and its bark has been used to treat rheumatism [1].

Phytochemical studies using the genus Pterodon have shown the presence of alkaloid compounds and triterpenoids in the bark, diterpenoids and isoflavones in the seeds, isoflavones and triterpenoids in the stems, and $\beta$-sitosterol and stigmasterol in the leaves [11-12]. Santos et al. [13] were able to infer that the essential oil and the isolated compounds of the leaves possess pharmacological potential and can be exploited for obtaining bioactive compounds.

Soxhlet is among the conventional extraction methods, with refluxing solvent for 6 to 12 hours. The disadvantages of this method, compared to other techniques for preparing solid samples, are the necessary time for the extraction and the large amount of solvent which, besides its high cost, also causes environmental problems. One of the most versatile and effective extraction procedures, which overcomes the difficulties mentioned above, is the methodology of Bligh and Dyer [14], a simplified version of the classical procedure which uses chloroform-methanol as proposed by Folch et al. [15]. Another advantage presented by methods based on binary mixture chloroform and methanol is the ability to efficiently extract both neutral and polar lipids [16].

Despite some disadvantages, such as toxicity of the solvents used and undesired extraction of the non-lipid contaminants from the organic phase, the methods of Folch et al. [15] and Bligh and Dyer [14] are widely used both as originally proposed or modified [17]. 
Thus, the present study aimed to evaluate the effect of extraction methods on the quality of bioactive compounds and antioxidant capacity in Pterodon emarginatus Vogel (sucupira) oil.

\section{MATERIAL AND METHODS}

\section{Materials}

Sucupira (Pterodon emarginatus Vogel) seeds were obtained in the Southeast region of Brazil, located at latitude $49^{\circ} 22^{\prime} 44^{\prime \prime S}$ and longitude $20^{\circ} 49^{\prime} 12^{\prime \prime} \mathrm{W}$. Three lots of seeds were acquired at different periods during the growing seasons of 2015 and 2016 and homogenized for subsequent analysis. The seeds were selected and despised those who had cracks, damage by insects and/or attacks of animals. After the selection of the seeds, these were dried in trays, the ambient temperature for reduction of moisture content $(<$ $10 \%)$.

The oils were extracted from the seeds through the extraction method with hot petroleum ether at $40-60^{\circ} \mathrm{C}$, in a Soxhlet extractor with reflux for 6 hours [18]. In the method by cold extraction, chloroform, methanol, and water were used in the ratio of 2:1:0.8 (v/v/v), respectively, according to the method of Bligh and Dyer [14]. The lipid fractions obtained by the different methods were packed in amber glass bottle, inertized with nitrogen gas, and stored at $-18^{\circ} \mathrm{C}$ until the moment of analysis.

\section{Chemicals}

A mixture composed of 37 fatty acid esters (Supelco, Bellefonte, USA), from C4:0 to C24:1, was used as standard for fatty acid composition, with a degree of purity between 99.1 and $99.0 \%$. Standards of $\alpha-, \beta-, \gamma^{-}$, and $\delta$-tocopherol (Supelco, Bellefonte, USA), with degrees of purity of $99.9,98.0,99.4$, and $99.6 \%$, respectively, were used as standards for tocopherol composition. Standards of cholesterol, campesterol, stigmasterol, $\beta$-sitosterol, and stigmastanol (Supelco, Bellefonte, USA), with degrees of purity of 99, 99, 95, 98, and $97.4 \%$, respectively, were used for phytosterols. DPPH free radical, synthetic antioxidant Trolox, FRAP reagent (TPTZ solution (2,4,6-tri(2-pyridyl)-1,3,5-triazine), $\mathrm{FeCl}_{3}$ and acetate buffer), were used in the antioxidant activity tests.

\section{Fatty acid profile by gas chromatography}

Potassium hydroxide in methanol and $n$-hexane were used to transesterify the lipid fractions of samples $(50 \mathrm{mg})$ to methyl esters, according to the AOCS Ce 2-66 [18]. Fatty acid methyl esters (FAMEs) were analyzed using a GC 3900 gas chromatograph (Varian Inc., Walnut Creek, CA, USA), equipped with a flame-ionization detector (GC-FID), injector split, and automatic sampler. FAMEs were separated by with the use of a CP-Sil 88 fused-silica capillary column $(60 \mathrm{~m} \times 0.25 \mathrm{~mm}$ i.d., $0.20 \mu \mathrm{m}$ film thickness, Chrompack, Varian Inc., Walnut Creek, CA, USA). The column oven temperature was initially held at $90^{\circ} \mathrm{C}$ for $4 \mathrm{~min}$, heated at $10^{\circ} \mathrm{C} / \mathrm{min}$ until $195^{\circ} \mathrm{C}$, and maintained at $195^{\circ} \mathrm{C}$ for $20.5 \mathrm{~min}$. The injector and detector temperatures were 230 and $250^{\circ} \mathrm{C}$, respectively. Samples of $1.0 \mu \mathrm{L}$ were injected, adopting a split ratio of 1:30. The carrier gas was hydrogen with a flow rate of 
$30 \mathrm{~mL} / \mathrm{min}$. FAMEs were identified by comparing their retention times with those of pure FAME standards (Supelco, Bellefonte, USA) under the same operating conditions. The integration software computed the peak areas, and percentages of fatty acid methyl esters were obtained as weight percentage by direct internal normalization.

\section{Tocopherols}

Tocopherol composition was determined by AOCS Ce 8-86 [18], using HPLC system (Varian Inc., Walnut Creek, CA, USA), equipped with a fluorescence detector. Forty mg of the lipid fractions of samples were diluted with $n$-hexane and $20 \mu \mathrm{L}$ sample were injected. The operating conditions were: $\lambda$ excitation $290 \mathrm{~nm}$ and $\lambda$ emission $330 \mathrm{~nm}$. A normal phase column (100 Si, $250 \mathrm{~mm}$ x $4.6 \mathrm{~mm}$ i.d., $0.5 \mu \mathrm{m}$ particle size, Microsorb, Varian Inc., Walnut Creek, CA, USA) was used with $n$-hexane/isopropanol $(99.5 / 0.5, \mathrm{v} / \mathrm{v})$ as a mobile phase. The system was operated isocratically, at a flow rate of $1.2 \mathrm{~mL} / \mathrm{min}$. The identification of tocopherols ( $\alpha$-, $\beta$-, $\gamma$ - and $\delta$-tocopherol) was conducted by comparing the HPLC retention time with those of standard compounds (Supelco, Bellefonte, USA), under the same operating conditions, and the quantification was based on an external standard method.

\section{Vitamin E activity}

Vitamin $E$ is represented as the equivalent of $\alpha$-tocopherol. The correction factor of 1.0 was used to calculate the $\alpha$-tocopherol content, while the concentrations of $\beta$ - and $\gamma$-tocopherol were multiplied by 0.25 , and the correction factor 0.01 was used for the amount of $\delta$-tocopherol. The isomers $\beta$-, $\gamma^{-}$, and $\delta$-tocopherols were calculated with a lower correction factor, in order to avoid the overvaluation of the $\alpha$-tocopherol equivalent [19].

\section{Phytosterols analysis}

Phytosterol composition measured using gas chromatography with saponification prior to the sample $(50-80 \mathrm{mg})$. The saponification was performed according to the methodology published by Duchateau et al. [20]. For the determination of the content of phytosterols, the AOCS method Ch 6-91 (2009) was used, with adaptations. The analysis was performed using a GC-2010 Plus gas chromatograph (Shimadzu, Chiyoda-ku, Tokyo, Japan), equipped with a flame-ionization detector (GC-FID), injector split and automatic sampler. Conditions of analysis: RTX 5 fused-silica capillary column (30 m x $0.25 \mathrm{~mm}$ i.d., $0.25 \mu \mathrm{m}$ film thickness, Restek, Shimadzu, Chiyoda-ku, Tokyo, Japan). The programming of column temperature was started at $100^{\circ} \mathrm{C}$, for $2 \mathrm{~min}$, heated at $15^{\circ} \mathrm{C} / \mathrm{min}$ until $260^{\circ} \mathrm{C}$, and maintained in isothermal condition for $35 \mathrm{~min}$. The temperatures used in the injector and the detector were 280 and $320^{\circ} \mathrm{C}$, respectively. Samples of $1.0 \mu \mathrm{L}$ were injected adopting a split ratio of 1:50. The carrier gas used was hydrogen with a linear speed of $40 \mathrm{~mL} / \mathrm{min}$. The phytosterols (cholesterol, campesterol, stigmasterol, $\beta$-sitosterol, and stigmastanol) were identified by comparison with the retention time of pure standards (Supelco, Bellefonte, USA), analyzed under the same conditions of the samples. The quantification of each isomer was performed by internal standardizing ( $5 \alpha$-cholestano- $3 \beta$-ol) based on the peak areas. 


\section{Total carotenoids}

The verification of the content of total carotenoids was performed by scanning spectrophotometry, according to the method described by Rodriguez-Amaya [21]. Quantification was calculated considering the absorption at the wavelength of maximum absorption and the A value of 2592, in petroleum ether, to calculate the total amount of carotenoids. Values were expressed as $\beta$-carotene, in $\mu \mathrm{g} / \mathrm{g}$ of the lipid fraction.

\section{Total phenolic compounds}

Total phenolics were quantified spectrophotometrically using the Folin-Ciocalteu reagent and gallic acid standard curve method, as described by Singleton and Rossi [22]. This method is based on the reduction of phosphomolybdic and phosphotungstic acids in alkaline solution and is mostly used for the determination of phenolic compounds in foods. The blue color produced by reduction of the Folin-Ciocalteu reagent by the phenolics was measured spectrophotometrically at $765 \mathrm{~nm}$ wavelength and the results were expressed in $\mathrm{mg}$ of gallic acid equivalent per gram of oil (GAE mg/g). The extraction of phenolic compounds was performed according to the method proposed by Parry et al. [23].

\section{Determination of the antioxidant capacity}

$D P P H$ scavenging capacity: DPPH' scavenging capacity of sucupira seed oil (100 mg) was determined according to the previously reported procedure using the stable 2,2-diphenyl-1-picryhydrazyl radical (DPPH') [24]. This method consists of spectrophotometric measurement of the intensity of color change in the solution, depending on the amount of DPPH. The reaction was initiated by mixing $1 \mathrm{~mL}$ of the oil, previously diluted with ethyl acetate $(1: 10, \mathrm{v} / \mathrm{v})$, with $4 \mathrm{~mL}$ of $\mathrm{DPPH}^{\cdot}\left(10^{-4} \mathrm{M}\right)$. The mixture was vigorously shaken and able to stand for $30 \mathrm{~min}$ in the dark; the resulting solution absorbance was measured at $517 \mathrm{~nm}$ using a UV-vis spectrophotometer (Shimadzu, Kyoto, Japan). The amount of sample needed to decrease the initial $\mathrm{DPPH}$ concentration by $50 \%\left(\mathrm{EC}_{50}\right)$ was calculated graphically by plotting the percentage of remaining $\mathrm{DPPH}^{\circ}$, estimated according to a standard curve, against sample concentrations (10, 25, 50, 75 and $100 \mathrm{mg} / \mathrm{mL}$ ).

Ferric Reducing Antioxidant Power: for the determination of antioxidant activity by reducing iron (FRAP) the method described by Szydłowska-Czerniak et al. [25] was used, with a mixture of $300 \mathrm{mM}$ acetate buffer, $10 \mathrm{mmol} / \mathrm{L}$ solution of TPTZ at $40 \mathrm{mM}$ hydrochloric acid and $20 \mathrm{mmol} / \mathrm{L}$ of aqueous solution of ferric chloride. This system was maintained at approximately $37^{\circ} \mathrm{C}$, for 30 minutes, and the absorbance was measured at $593 \mathrm{~nm}$. For quantification, a calibration curve was generated using Trolox as standard in concentrations from 50 to $2000 \mathrm{mmol} / \mathrm{L}$, from which the equation of the line $y=0.001 x+0.040$ was obtained, with a correlation coefficient of 0.9900 and the result expressed as $\mu \mathrm{mol}$ Trolox/100 g.

Capturing the free radical $A B T S^{++}$: the total antioxidant activity, by the method of 
capturing the free radical $\mathrm{ABTS}^{\circ+}$, was performed according to the method described by $\mathrm{Re}$ et al. [26]. The radical $\mathrm{ABTS}^{++}$was formed by the reaction of the solution of $7 \mathrm{mmol} / \mathrm{L}$ with the solution of potassium persulfate in $140 \mathrm{mmol} / \mathrm{L}$, kept in the dark for $12-16$ hours. The reading of the samples was performed at $734 \mathrm{~nm}$, after 6 minutes of reaction. For quantification, a calibration curve was generated by using Trolox as standard, in concentrations from 50 to $2000 \mathrm{mmol} / \mathrm{L}$, from which the equation of the line $y=-0.0003 x+0.4887$ was obtained, with a correlation coefficient of 0.9998 and the result expressed as $\mu \mathrm{mol}$ Trolox $/ 100 \mathrm{~g}$.

\section{Oxidative stability index}

The oxidative stability index was determined by the use of a Rancimat instrument (Metrohm Ltd., Herisau, Switzerland), following the AOCS method Cd 12b-92 [18]. Oxidation was carried out at $100^{\circ} \mathrm{C}$, with an airflow rate of $20 \mathrm{~L} / \mathrm{h}, 3 \mathrm{~g}$ of the lipid fractions of the samples, and $60 \mathrm{~mL}$ of distilled water in vials containing electrodes. The oxidative stability index was defined as the hours for the oil sample to develop a measurable rancidity.

\section{Statistical analysis}

All the experiments were carried out in triplicate. The results were expressed as means \pm SD (standard deviation). The results were subjected to analysis of variance (ANOVA) and Tukey's studentized range test using ESTAT, version 2.0.

\section{RESULTS AND DISCUSSION}

\section{Bioactive substances}

A detailed identification and quantification of bioactive compounds present in the lipid fractions of Pterodon emarginatus seeds, extracted by Soxhlet and Bligh \& Dyer, are presented in Table 1. The lipid fraction yield obtained by Soxhlet was of $39.15 \%$. High total lipids found in seeds can be considered economically attractive for industrial extraction, especially when compared with other oilseeds, including corn and soybeans, which show lipid content from 3.1 to $5.7 \%$ and from 18 to $20 \%$, respectively [27]. 
Table 1. Bioactive substances present in lipid fractions of Pterodon emarginatus, obtained by Soxhlet and Bligh \& Dyer methods.

\begin{tabular}{cccc}
\hline Compounds & $\begin{array}{c}\text { Molecular } \\
\text { formula }\end{array}$ & Soxhlet & Bligh \& Dyer \\
\hline Lipids (\%) & & $39.15 \pm 0.09^{\mathrm{a}}$ & $31.65 \pm 0.03^{\mathrm{b}}$ \\
\hline Fatty acids (\%) & & & \\
Capric (C10:0) & $\mathrm{C}_{10} \mathrm{H}_{20} \mathrm{O}_{2}$ & $23.81 \pm 0.03$ & $21.19 \pm 0.04$ \\
Lauric (C12:0) & $\mathrm{C}_{12} \mathrm{H}_{24} \mathrm{O}_{2}$ & $11.06 \pm 0.04$ & $9.71 \pm 0.06$ \\
Palmitic (C16:0) & $\mathrm{C}_{16} \mathrm{H}_{32} \mathrm{O}_{2}$ & $6.62 \pm 0.02$ & $7.72 \pm 0.03$ \\
Palmitoleic (C16:1) & $\mathrm{C}_{16} \mathrm{H}_{30} \mathrm{O}_{2}$ & $1.57 \pm 0.03$ & $1.67 \pm 0.01$ \\
Stearic (C18:0) & $\mathrm{C}_{18} \mathrm{H}_{36} \mathrm{O}_{2}$ & $2.22 \pm 0.02$ & $2.71 \pm 0.05$ \\
Oleic (C18:1 n-9) & $\mathrm{C}_{18} \mathrm{H}_{34} \mathrm{O}_{2}$ & $17.80 \pm 0.05$ & $18.27 \pm 0.02$ \\
Linoleic (C18:2 n-6) & $\mathrm{C}_{18} \mathrm{H}_{32} \mathrm{O}_{2}$ & $28.42 \pm 0.01$ & $31.29 \pm 0.14$ \\
Araquidic (C20:0) & $\mathrm{C}_{20} \mathrm{H}_{40} \mathrm{O}_{2}$ & $5.43 \pm 0.02$ & $4.49 \pm 0.02$ \\
Gadolenic (C20:1) & $\mathrm{C}_{20} \mathrm{H}_{38} \mathrm{O}_{2}$ & $1.74 \pm 0.03$ & $1.63 \pm 0.03$ \\
a-linolenic (C18:3 n3) & $\mathrm{C}_{18} \mathrm{H}_{30} \mathrm{O}_{2}$ & $1.33 \pm 0.01$ & $1.31 \pm 0.02$ \\
Saturated & & $49.15 \pm 0.03^{\mathrm{a}}$ & $45.82 \pm 0.16^{\mathrm{b}}$ \\
Monounsaturated & & $21.11 \pm 0.03^{\mathrm{b}}$ & $21.57 \pm 0.04^{\mathrm{a}}$ \\
Polyunsaturated & & $29.75 \pm 0.01^{\mathrm{b}}$ & $32.61 \pm 0.13^{\mathrm{a}}$ \\
\hline
\end{tabular}

Tocopherols (mg/kg)

y-tocopherol

$\mathrm{C}_{28} \mathrm{H}_{48} \mathrm{O}_{2}$

$5.17 \pm 0.06^{\mathrm{a}}$

$4.17 \pm 0.06^{b}$

$\delta$-tocopherol

$\mathrm{C}_{27} \mathrm{H}_{46} \mathrm{O}_{2}$

$16.80 \pm 0.10^{\mathrm{a}}$

$15.53 \pm 0.06^{\mathrm{b}}$

Total

$21.97 \pm 0.06^{\mathrm{a}}$

$19.70 \pm 0.10^{b}$

Vitamin $\mathrm{E}^{*}$

$1.46 \pm 0.01^{\mathrm{a}}$

$1.20 \pm 0.01^{b}$

Phytosterols (mg/100 g)

Cholesterol

$\mathrm{C}_{27} \mathrm{H}_{46} \mathrm{O}$

$1.96 \pm 0.01^{\mathrm{a}}$

$1.96 \pm 0.01^{a}$

Campesterol

$\mathrm{C}_{28} \mathrm{H}_{48} \mathrm{O}$

$33.46 \pm 0.03^{\mathrm{a}}$

$8.37 \pm 0.01^{b}$

Stigmasterol

$\mathrm{C}_{29} \mathrm{H}_{48} \mathrm{O}$

$2.79 \pm 0.01^{\mathrm{a}}$

$2.79 \pm 0.01^{a}$

$\beta$-sitosterol

$\mathrm{C}_{29} \mathrm{H}_{50} \mathrm{O}$

$8.36 \pm 0.01^{\mathrm{b}}$

$11.16 \pm 0.01^{\mathrm{a}}$

Total

$46.58 \pm 0.03^{a}$

$24.29 \pm 0.01^{b}$

Total carotenoids $(\mu \mathrm{g} / \mathrm{g})$

$\beta$-carotene

$\mathrm{C}_{40} \mathrm{H}_{56}$

$12.97 \pm 0.16^{\mathrm{a}}$

$9.84 \pm 0.16^{b}$

Total phenolic compounds (mg GAE/g)

Gallic acid

$\mathrm{C}_{7} \mathrm{H}_{6} \mathrm{O}_{5}$

$5.54 \pm 0.23^{b}$

$10.84 \pm 0.08^{a}$

The results represent the mean \pm standard deviation of three determinations followed by the same letters do not differ by the Tukey test $(p>0.05)$.

*Activity of vitamin $E$ expressed as the equivalent of $\alpha$-tocopherol, ${ }^{\star *}$ Milligram of gallic acid equivalents per gram of sample. 
According to Table 1, in the lipid fractions of Pterodon emarginatus seeds, 10 fatty acids were detected. Saturated fatty acids were found in higher concentration in Soxhlet extraction (49.15\%), with emphasis on capric (C10:0) and lauric (C12:0) fatty acids, whereas higher concentrations of unsaturated fatty acids were found in Bligh \& Dyer extraction, with linoleic and oleic acids in the majority: 31.29 and $18.27 \%$ respectively (Figure 1 ).
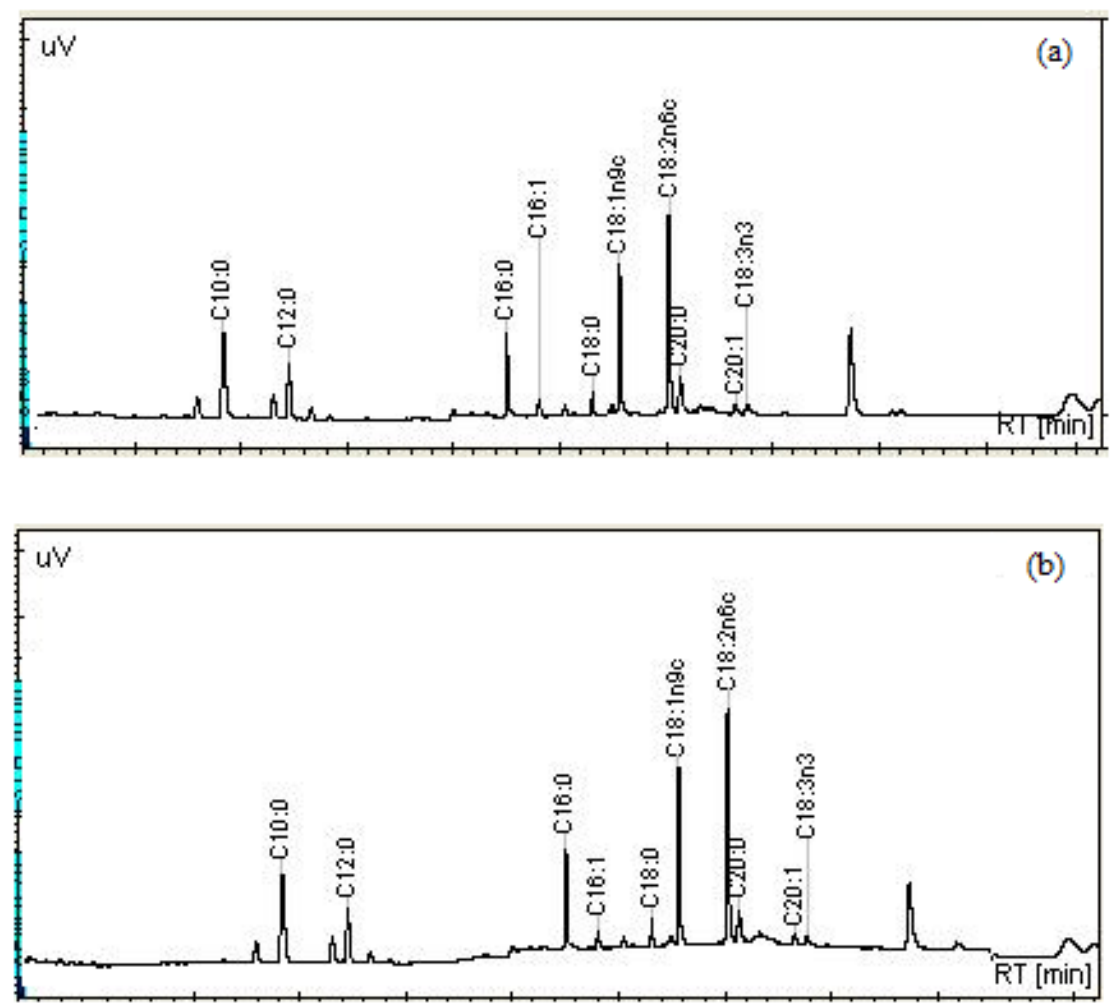

Figure 1. Fatty acid profile by gas chromatography from the sucupira oils extracted by Soxhlet (a) and Bligh \& Dyer (b) methods.

There is a great interest in the industrial vegetable oils with a high content of lauric acid, since such acid is used primarily as a flavoring in the food industry and as a surfactant in cosmetics, soaps, and detergents, for its high foaming power and for being biodegradable [28]. Another important aspect of lauric acid is its antifungal activity which has been shown to act against pathogenic fungi [29]. Moreover, the use of oils that are rich in lauric acid provides healthier blood lipid profile than the use of oils that are rich in trans fatty acids [30], such as myristic [31] or palmitic [32], since these fatty acids promote increased HDL cholesterol differently.

The high percentage of oleic acid in oils makes them desirable in terms of nutrition and cooking, representing high stability when used for heating. The high degree of unsaturation of oils allows them to oxidize easily when used at elevated temperatures. For example, linoleic acid oxidizes about 50 times faster than oleic acid [33]. Thus, the industries of edible oils have been trying to process vegetable oils with high content of oleic acid. The predominance of medium chain fatty acids (C6-C12) and high oleic acid content in the sucupira oil may represent an additional option as an ingredient for the industry of food processing [34]. 
Concerning the tocopherols, while $\alpha$-tocopherol presents the highest biological activity, such as vitamin $E, y$-and $\delta$-tocopherol shows higher antioxidant activity [35-36].The lipid fraction extracted from the sucupira seeds by Soxhlet showed a significant amount of total tocopherols $(p<0.05)$, even higher than the oil extracted by Bligh \& Dyer. The isomer $\delta$-tocopherol was found in greater amounts in this fraction $(16.80 \mathrm{mg} / \mathrm{kg})$, and $\alpha$ - and $\beta$-tocopherol were not detected.

According to the Codex Alimentarius Commission [37], corn (268-2468 mg/kg), soybean (89-2307 mg/kg), and sesame (521-983 mg/kg) oils have $\mathrm{y}$-tocopherol as predominant. Although $\delta$-tocopherol is found naturally in small quantities in lipids, Tuberoso et al. [38] found the isomer in peanut $(13.4 \mathrm{mg} / \mathrm{kg})$, sunflower $(9.2 \mathrm{mg} / \mathrm{kg})$, and canola $(6.1$ $\mathrm{mg} / \mathrm{kg}$ ) oils, and soybean oil presented 154-934 mg/kg [37].

Phytosterols are constituents that are present in lower amounts in the unsaponifiable fraction of vegetable matter. When evaluating the composition of sterols in lipid fractions of sucupira seeds by Soxhlet, there was a significant difference $(p<0.05)$, with higher levels of total phytosterols $(46.58 \mathrm{mg} / 100 \mathrm{~g})$, compared with the Bligh \& Dyer system. This value coincides with the range of total phytosterols found in coconut and palm oils [37].

The concentration of campesterol was about four times higher in the oil extracted by Soxhlet and, as expected, cholesterol was the sterol present in lower amounts in the lipid fractions studied, with levels of $1.96 \mathrm{mg} / 100 \mathrm{~g}$, and $\beta$-stigmasterol and sitosterol were found in all samples analyzed.

According to the Code of Federal Regulations [39], diets which are low in saturated fat and cholesterol and that include $2 \mathrm{~g}$ /day of phytosterols may reduce the risk of heart diseases. Thus, a clinical study showed that the ingestion of 1.6 to $2 \mathrm{~g}$ of phytosterols a day was able to reduce cholesterol absorption by the intestine by $30 \%$ and lipoprotein blood levels of low density cholesterol (LDL-c) by $8-10 \%$. In this study, it was concluded that the intake of up to $3 \mathrm{~g} /$ day of phytosterols is safe and effective to achieve a significant reduction of cholesterolemia [40].

The concentration of carotenoids in oils is affected by the maturity stage of fruits and the conditions of extraction and storage. Oils extracted from ripe fruits may contain a higher amount of carotenoid pigments, while those obtained from partially ripe fruits have higher concentrations of chlorophyll [41]. As shown in Table 1, the level of total carotenoids, expressed as $\beta$-carotene, was significantly higher in the oil extracted by Soxhlet, with 12.97 $\mathrm{mg} / \mathrm{g}$.

Tuberoso et al. [38] quantified $\beta$-carotene in flaxseed, grape, corn, peanut, pumpkin, canola, soy, sunflower, and olive oils. Quantities above $1.0 \mu \mathrm{g} / \mathrm{g}$ were found only in olive $(6.9 \mu \mathrm{g} / \mathrm{g})$, pumpkin $(5.7 \mu \mathrm{g} / \mathrm{g})$, and canola $(1.7 \mu \mathrm{g} / \mathrm{g})$ oils.

According Gaméz-Meza et al. [42], phenolic compounds are important since they contribute to antioxidant activity: the extraction of these compounds from natural products is strongly influenced by the solvent used. It has been observed that the higher the polarity of the extracting solvent, the greater the amount of phenolic compounds. Thus, methods based 
on the binary mixture, chloroform and methanol, have the ability to efficiently extract lipids.

According to the results presented in Table 1, the content of total phenolic compounds was found significantly higher by Tukey test $(p<0.05)$ in the lipid fraction extracted by Bligh \& Dyer, with a content of $10.84 \mathrm{mg} \mathrm{GAE} / \mathrm{g}$.

\section{Antioxidant capacity}

Results of the evaluation of antioxidant capacity, effective concentration $\left(\mathrm{EC}_{50}\right)$, and oxidative stability index of the lipid fraction extracted from the seeds of Pterodon emarginatus are reported in Table 2 . The lipid fractions showed scavenging activity DPPH', presenting antioxidant capacity higher than $50 \%$, with a maximum value of $95.18 \%$ in Soxhlet extraction.

Table 2. Antioxidant capacity and oxidative stability index of the lipid fractions of Pterodon emarginatus, obtained by Soxhlet and Bligh \& Dyer systems.

\begin{tabular}{ccc}
\hline Antioxidant capacity & Soxhlet & Bligh \& Dyer \\
\hline $\operatorname{DPPH}^{\circ}(\%)$ & $95.18 \pm 0.26^{\mathrm{a}}$ & $88.71 \pm 0.13^{\mathrm{b}}$ \\
$\mathrm{EC}_{50}(\mathrm{~g}$ lipid fraction/g DPPH $)$ & 7.10 & 43.68 \\
FRAP $\left(\mu \mathrm{mol}\right.$ Trolox $/ 100 \mathrm{~g}$ lipid fraction) $^{\circ}$ & $172.70 \pm 0.52^{\mathrm{b}}$ & $360.57 \pm 5.83^{\mathrm{a}}$ \\
ABTS $^{\circ+}(\mu \mathrm{mol}$ Trolox/100 g lipid fraction) & $89.46 \pm 0.77^{\mathrm{b}}$ & $162.01 \pm 0.19^{\mathrm{a}}$ \\
Oxidative stability index $(\mathrm{h})$ & $0.41 \pm 0.02^{\mathrm{b}}$ & $64.07 \pm 0.71^{\mathrm{a}}$
\end{tabular}

The results represent the mean \pm standard deviation of three determinations followed by the same letters do not differ by the Tukey test $(p>0.05)$.

$\mathrm{EC}_{50}$, quantity of antioxidant needed to decrease the initial $\mathrm{DPPH}{ }^{\circ}$ concentration by $50 \%$.

$E C_{50}$ values, obtained by linear regression for lipid fractions extracted from the sucupira seeds by Soxhlet and Bligh \& Dyer, showed high coefficients of determination, 0.990 and 0.995, respectively. The quantities of oil necessary to decrease the initial $\mathrm{DPPH}^{\circ}$ concentration by $50 \%\left(\mathrm{EC}_{50}\right)$ were 7.1 and $43.68 \mathrm{~g}$ lipid fraction $/ \mathrm{g} \mathrm{DPPH}{ }^{\circ}$ for lipid fractions extracted by Soxhlet and Bligh \& Dyer, respectively. These values are much lower than those obtained by Arranz et al. [43] in oils extracted from walnut (1514.3 g oil/g DPPH'), almond (712.2 $\mathrm{g}$ oil $\left./ \mathrm{g} \mathrm{DPPH}^{\circ}\right)$, hazel (478.5 g oil/g DPPH'), and pistachio (377.9 g oil $/ \mathrm{g}$ $\left.\mathrm{DPPH}^{\circ}\right)$. On the other hand, it is larger than that found by Malacrida and Jorge [44] in passion fruit seeds oil extracted by Soxhlet method. Gharibzahedi et al. [45] showed that Persian walnut oil extracted by modified Bligh and Dyer method had the highest efficiency to scavenge DPPH radicals compared to the maceration extraction.

It is observed that the oils of sucupira seeds showed similar behavior between FRAP and $\mathrm{ABTS}^{\cdot+}$ systems. The FRAP system is commonly used to study the antioxidant capacity of fruits and plants. 
The lipid fractions of sucupira demonstrated antioxidant activity of 360.57 and 172.70 $\mu \mathrm{mol}$ Trolox/100 $\mathrm{g}$ when assessed with FRAP methodology, and of 162.01 and $89.46 \mu \mathrm{mol}$ Trolox $/ 100 \mathrm{~g}$ with the ABTS ${ }^{++}$method, both with significantly higher values by the method of Bligh \& Dyer. Contreras-Calderón et al. [46] studied the antioxidant capacity of peel, pulp, and seeds of 24 exotic fruits from Colombia and found variation from 4.93 to $1690 \mu \mathrm{mol}$ Trolox/g for the FRAP system and 13.9 to $1700 \mu \mathrm{mol}$ Trolox/g for the ABTS ${ }^{\circ+}$ system.

The oxidative stability is an important parameter to evaluate the possible applications of oils in foods and other commercial products. A significant difference may be observed in the rate of oxidative stability among extraction methods, and the method Bligh \& Dyer presented the highest stability $(64.07 \mathrm{~h})$. This is probably due to the formation of a biphasic system from the proportions added during the solvent extraction process in the method of Bligh \& Dyer, aiding in the extraction of polar compounds present in the sample. Allied to this, phytochemical studies on the genre Pterodon have revealed the presence of diterpenes [47-48] and isoflavones [49] in the seed oil.

\section{CONCLUSION}

From the data obtained in this study it was found that the methodology chosen for the extraction of the lipid fraction extracted can affect its quantity and quality. The Soxhlet extraction showed better yield in total lipids and was more efficient to extract tocopherols, phytosterols, and carotenoids, besides presenting better antioxidant capacity by DPPH: However, this extraction method presented insufficient capacity to extract lipid components of the sample, as evidenced by the results of phenolic compounds. On the other hand, the method of Bligh \& Dyer preserved the fatty acid profile and was effective to extract higher phenolic content and to present superior antioxidant capacity when assessed by FRAP, $\mathrm{ABTS}^{\circ+}$, and oxidative stability index. The lipid fractions of sucupira seeds are good sources of oleic, lauric, and capric fatty acids, viable sources of carotenoids and phenolic compounds with high antioxidant activity and oxidative stability. The application of raw materials for the food, chemical, and pharmaceutical industries may be suggested. However are needed the futher studies on the research gaps.

Acknowledgments: The authors are grateful for the assistance of the São Paulo Research Foundation (FAPESP) and the National Council for Scientific and Technological Development (CNPq).

Conflicts of Interest: The authors declare no conflict of interest. The funders had no role in the design of the study; in the collection, analyses, or interpretation of data; in the writing of the manuscript, or in the decision to publish the results. 


\section{REFERENCES}

1. Lorenzi, H.; Matos, F.J.A. Plantas medicinais no Brasil: nativas e exóticas. Nova Instituto Plantarum: Odessa, 2002.

2. Mascaro, U.C.P.; Teixeira, D.F.; Gilbert, B. Avaliação da sustentabilidade da coleta de frutos de "sucupira branca" (Pterodon emarginatus Vog.) após queda espontânea. Rev Bras Plantas Med 2004, 7, 23-25.

3. Mahajan, J.R.; Monteiro, M.B. New diterpenoids from Pterodon emarginatus Vog. J Chem Soc Perkin 1 1973, 5, 520-525.

4. Galceran, C.B.; Sertie, J.A.A.; Lima, C.S.; Carvalho, J.C.T. Anti-inflammatory and analgesic effects of $6 \alpha, 7 \beta$-dihydroxy-vouacapan-17 $\beta$-oic acid isolated from Pterodon emarginatus Vog. fruits. Inflammopharmacol 2011, 19,139-143.

5. Omena, M.C.; Bento, E.S.; De Paula, J.E.; Sant'Ana, A.E. Larvicidal diterpenes from Pterodon polygalaeflorus. Vector Borne Zoonotic Dis 2006, 6, 216-222.

6. Nunan, E.A.; Carvalho, M.G.; Piló-Veloso, D.; Turchetti-Maia, R.M.M.; Ferreira-Alves, D.L. Furane diterpenes with anti- and proinflammatory activity. Braz $J$ Med Biol Res 1982, 15, 450-451.

7. Almeida, M.E.L.; Gottilieb, O.R. The chemistry of Brazilian Leguminosae: further isoflavones from Pterodon appariciori. Phytochemistry 1975, 14, 2716-2720.

8. Raposo, N.R.B.; Dutra, R.C.; Ferreira, A.S. Biological properties of Sucupira Branca (Pterodon emarginatus) seeds and their potential usage in health treatments. In Nuts and seeds in health and disease prevention; Preedy, V.R.; Watson, R.R.; Patel, V.B., Eds.; Academic Press: London, 2011.

9. Carvalho, J.C.; Sertié, J.A.A.; Barbosa, M.V.J.; Patrício, K.C.M.; Caputo, L.R.G.; Sarti, S.J.; Ferreira, L.P.; Bastos, J.K Anti-inflammatory activity of the crude extract from the fruits of Pterodon emarginatus Vog. J Ethnopharmacol 1999, 64, 127-133.

10. Paula, F.B.A.; Gouvêa, C.M.C.P.; Alfredo, P.P.; Salgado, I. Protective action of a hexane crude extract of Pterodon emarginatus fruits against oxidative and nitrosative stress induced by acute exercise in rats. BMC Complement Altern Med 2005, 5, 17.

11. Santos, A.P.; Zatta, D.T.; Moraes, W.F.; Bara, M.T.F.; Ferri, P.H.; Silva, M.R.R.; Paula, J.R. Composição química, atividade antimicrobiana do óleo essencial e ocorrência de esteroides nas folhas de Pterodon emarginatus Vogel, Fabaceae. Rev Bras Farmacogn 2010, 20 , 891-896.

12. Marques, D.D.; Machado, M.I.L.; Carvalho, M.G.; Meleira, L.A.C.; Braz Filho, R. Isoflavonoids and triterpenoids isolated from Pterodon polygalaeflorus. J Braz Chem Soc 1998, 9, 295-301.

13. Santos, A.P.; Zatta, D.T.; Moraes, W.F.; Bara, M.T.F.; Ferri, P.H.; Silva, M.R.R.; Paula, J.R. Composição química, atividade antimicrobiana do óleo essencial e ocorrência de esteroides nas folhas de Pterodon emarginatus Vogel, Fabaceae. Rev Bras Farmacogn 2010, 20, 891-896.

14. Bligh, E.G.; Dyer, W.J. A rapid method of total lipid extraction and purification. Can J Biochem 
Physiol 1959, 37, 911-917.

15. Folch, J.; Lees, M.; Stanley, G.H.S. A simple method for the isolation and purification of total lipides from animal tissues. J Biol Chem 1957, 226, 497-509.

16. Kates, M. Techniques of lipidology: isolation, analysis and identification of lipids. Elsevier Applied Science London, 1972.

17. Christie, W.W. Lipid analysis. Pergamon Press: Oxford, 1982.

18. AOCS. Official and tentative methods of the American Oil Chemists' Society. Champaing: AOCS Press; 2009.

19. Kornsteiner, M.; Wagner, K.H.; Elmadfa, I. Tocopherols and total phenolics in 10 different nut types. Food Chem 2006, 98, 381-387.

20. Duchateau, G.S.M.J.E.; Bauer-Plank, C.G.; van der Ham, M.; Boerma, J.A.; van Rooijen, J.J.M.; Zandbelt, P.A. Fast and accurate method for total 4-desmethyl sterol(s), content in spreads, fat-blends and raw materials. J Am Oil Chem Soc 2002, 79, 273-278.

21. Rodriguez-Amaya, D.B. A guide to carotenoids analysis in food. ILSI Press: Washington, 1999.

22. Singleton, V.L.; Rossi, J.A. Colorimetry of total phenolics with phosphomolybdic-phosphotungstic acid reagents. Am J Enol Vitic 1965, 16, 144-158.

23. Parry, J.; Su, L.; Luther, M.; Zhou, K.; Yurawecz, M.P.; Whittaker, P.; Yu, L. Fatty acid composition and antioxidant properties of cold-pressed marionberry, boysenberry, red raspberry, and blueberry seed oils. J Agric Food Chem 2005, 53, 566-573.

24. Kalantzakis, G.; Blekas, G.; Pegklidou, K.; Boskou, D. Stability and radicalscavenging activity of heated olive oil and other vegetable oils. Eur J Lipid Sci Technol 2006, 108, 329-335.

25. Szydłowska-Czerniak, A.; Karlovits, G.; Dianoczki, C.; Recseg, K.; Szlyk, E. Comparison of two analytical methods for assessing antioxidant capacity of rapeseed and olive oils. J Am Oil Chem Soc 2008, 85, 141-149.

26. Re, R.; Pellegrini, N.; Proteggente, A.; Pannala, A.; Yang, M.; Rice-Evans, C. Antioxidant activity applying an improved ABTS radical cation decolorization assay. Free Radical Bio Med 1999, 26, 1231-1237.

27. O'Brien, R.D. Fats and oils: formulating and processing for applications. CRC Press: Boca Raton, 2004.

28. Crews, C.; Houg, P.; Godward, J.; Brereton, P.; Lees, M.; Guiet, S. Quantification of the main constituents of some authentic grape-seed oil of different origin. J Agric Food Chem 2006, 54, 6261-6265.

29. Walters, D.R.; Walker, R.L.; Walker, K.C. Lauric acid exhibits antifungal activity against plant pathogenic fungi. J Phytopathol 2003, 151, 228-230.

30. Mensink, R.P.; Zock, P.L.; Kester, A.D.; Katan, M.B. Effects carbohydrates on the ratio of serum total to HDL cholesterol and on serum lipids and apolipoproteins: a metaanalysis of 60 controlled 
trials. Am J Clin Nutr 2003, 77, 1146-1155.

31. Park, S.; Snook, J.T.; Bricker, L.; Morroco, M.; Van Voorhis, R.; Stasny, E.; Park, S., Lee, M. S. Relative effects of high saturated fatty acid levels in meat, dairy products, and tropical oils on serum lipoproteins and low-density lipoprotein degradation by mononuclear cells in healthy males. Metabolism 1996, 45, 550-558.

32. Temme, E.H.M.; Mensink, R.P.; Hornstra, G. Comparison the effects diets enriched in lauric, palmitic, or oleic acids on serum lipids and lipoproteins in healthy women and men. Am J Clin Nutr 1996, 63, 897-903.

33. Brinkmann, B. Quality criteria of industrial frying oils and fats. Eur J Lipid Sci Technol 2000, 102, 539-541.

34. Roos, N.M.; Schouten, E.G.; Katan, M.B. 2001. Consumption of a solid fat rich in lauric acid results in a more favorable serum lipid profile in healthy men and women than consumption of a solid fat rich in trans-fatty acids. J Nutr 2001, 131, 242-245.

35. Schmidt, S.; Pokorný, J. Potential application of oilseeds as sources of antioxidants for food lipids - a review. Czech J Food Sci 2005, 23, 93-102.

36. Shahidi, F.; Naczk, M. Food phenolics: sources, chemistry, effects and applications. Technomic: Lancaster, 1995.

37. Codex Alimentarius Commission. Codex-Stan 210: codex standard for named vegetable oils. Rome; 2009.

38. Tuberoso, C.I.G.; Kowalczyk, A.; Sarritzu, E.; Cabras, P. Determination of antioxidant compounds and antioxidant activity in commercial oilseeds for food use. Food Chem 2007, 103, 1494-1501.

39. Code of Federal Regulations. Food labeling health claim; phytosterols and risk of coronary heart disease; proposed rule. Food and Drug Administration. 21 CFR Part 101. Federal Register 75, 76526-76571; 2010.

40. Marangoni, F.; Poli, A. Phytosterols and cardiovascular health. Pharmacol Res 2010, 61, 193-199.

41. Ramadan, M.F.; Morsel, J.T. Oil cactus pear (Opuntia ficus-indica L.). Food Chem 2003, 82, 339-345.

42. Gaméz-Meza, N.; Noriega-Rodríguez, J.A.; Medina-Juárez, L.A.; Ortega-García, J.; Cázarez-Casanova, R.; Angulo-Guerrero, O. Antioxidant activity in soybean oil of extracts from Thompson grape bagasse. J Am Oil Chem Soc 1999, 76, 1445-1447.

43. Arranz, S.; Pérez-Jiménez, J.; Saura-Calixto, F. Antioxidant capacity of walnut (Juglans regia L.): contribution of oil and defatted matter. Eur Food Res Technol 2008, 227, 425-431.

44. Malacrida, C.R.; Jorge, N. Yellow passion fruit seed oil (Passiflora edulis f. flavicarpa): physical and chemical characteristics. Braz Arch Biol Technol 2012, 55, 127-134. 
45. Gharibzahedi, S.M.T.; Mousavi, S.M.; Hamedi, M.; Rezaei, K.; Khodaiyan, F. Evaluation of physicochemical properties and antioxidant activities of Persian walnut oil obtained by several extraction methods. Ind Crops Prod 2013, 45, 133-140.

46. Contreras-Calderón, J.; Calderón-Jaimes, L.; Guerra-Hernández, E.; García-Villanova, B. Antioxidant capacity, phenolic content and vitamin $C$ in pulp, peel and seed from 24 exotic fruits from Colombia. Food Res Int 2011, 44, 2047-2053.

47. Fascio, M.; Mors, W.B.; Gilbert, B.; Mahajan, J.R.; Monteiro, M.B.; Santos Filho, D.; Vichnewski, W. Diterpenoids furans from Pterodon pubescens species. Phytochemistry 1976, 15, 201-203.

48. Arriaga, A.M.C.; Castro, M.A.B.; Silveira, E.R.; Braz-Filho, R. Further diterpenoids isolated from Pterodon polygalaeflorus. J Braz Chem Soc 2000, 11, 187-190.

49. Braz Filho, R.; Gottlieb, O.R.; Assumpção, R.M.V. Chemistry of Brazilian Leguminosae. XXXIV Isoflavones of Pterodon pubenscens. Phytochemistry 1971, 10, 2835-2836.

(C) 2018 by the authors. Submitted for possible open access publication under the terms and conditions of the Creative Commons Attribution (CC BY NC) license (https://creativecommons.org/licenses/by-nc/4.0/). 